\title{
К ВОПРОСУ ОБ ЭФФЕКТИВНОСТИ РЕАЛИЗАЦИИ АДМИНИСТРАТИВНО-ПРАВОВЫХ СРЕДСТВ ПРОТИВОДЕЙСТВИЯ КОРРУПЦИИ В СОЦИАЛЬНОЙ СФЕРЕ
}

\begin{abstract}
Аннотация. Предмет статьи посвящен рассмотрению проблемы реализации административно-правовых средств противодействия коррупции в социальной срере. Обозначенная проблема обусловлена правовыми и организационными проблемами, которые имеют место в деле противодействия коррупционной деликтности в социальной сфере. Актуальность данной проблеме добавляет тот факт, что вопросы противодействия коррупции особенно чувствительны именно в социальной сфере, поскольку от нее зависит качество жизни людей. Автором обосновывается необходимость повышать эффективность реализации административно-правовых средств противодействия коррупции в социальной срере. На основе проведенного исследования в статье предлагаются усовершенствовать как материальные, так и процессуальные административно-правовые средства противодействия коррупции в социальной сфере. Методологическую основу статьи составили современные достижения теории познания. В процессе исследования применялись общефилософский, теоретический, общефилософские методы (диалектика, системный метод, анализ, синтез, аналогия, дедукция, наблюдение, моделирование), традиционно правовые методы (формально-логический), а также методы, используемые в конкретно-социологических исследованиях (статистические, экспертные оценки и др.). Важный вывод, который сделан по итогам исследования, состоит в том, что в настоящее время для обеспечения правопорядка в сочиальной сфере необходимо совершенствовать качество самых разнообразных административно-правовых средств противодействия коррупционным правонарушениям в социальной сфере. Основным вкладом, который сделан авторами в настоящей статье это необходимость развития правового регулирования противодействия коррупции социальной срере с помощью административно-правовых средств.
\end{abstract}

Ключевые слова: деликт, коррупция, правонарушение, преступление, наказание, ответственность, здравоохранение, субъект, сфера, состав.

Abstract. The article studies the problem of application of administrative instruments of combating corruption in the social sphere. This issue is conditioned by legal and organizational problems of combating corruption in the social sphere. The problem of corruption in the social sphere is particularly important since it affects the quality of people's life. The author explains the necessity to increase the effectiveness of administrative instruments of combating corruption in the social sphere. The author suggests improving both material and procedural administrative instruments of combating corruption in the social sphere. The research methodology is based on the modern achievements of epistemology. The author applies general philosophical and theoretical methods (dialectics, the system method, analysis, synthesis, analogy, deduction, observation and modeling), traditional legal methods (formal logical) and the methods of special sociological research (statistical, expert assessments, etc.). The author concludes that at present, in order to ensure legality in the social sphere, it is necessary to improve the quality of various administrative instruments of combating corruption in the social sphere. The author states the necessity to develop legal regulation of combating corruption in the social sphere with the help of administrative instruments.

Key words: public health, responsibility, punishment, crime, offence, corruption, delict, subject, sphere, composition.

ффективность реализации административно-правовых средств, как и эффективность правовых норм в целом, относиться скорее к конкртено-социологическим, чем к сугубо юридическим понятиям, т.е. не может рассматриваться в рамках теории юридического позитивизма. 


\section{Административное и муниципальное право 9 (105) • 2016}

Действительно, в теории права распространено мнение в соответствии с которым эффективность нормативного воздействия на общественные отношения не ограничивается совершенством позитивного права, т.е. нормы, а находиться в плоскости практического применения, или, точнее, фактического результата, который позволяет выявить практические недостатки норм права, а совершенствование последнего осуществляется с учетом конкретных недостатков выявленных в процессе применения нормативного материала. Отмечается, что эффективность любой нормы права является «...соответствием объективным закономерностям, близости к оптимальному масштабу поведения, фактического результата к цели...» [1], определенной правовой нормой. Таким образом, эффективность правовой нормы заключается не в ее абстрактном исследовании, а в исследовании ее результата воздействия на поведение людей и оценке соответствия данного результата с целью для которой она была создана.

Вопрос эффективности действия норм права приобрел особую актуальность в оценке мер противодействия коррупции, а точнее в связи с неэффективностью последних. Действительно, сегодня стало очевидным, что несмотря на постоянное совершенствование административно-правовых средств борьбы с коррупцией и их соответствие международно-правовым стандартам, эффективность борьбы с коррупцией оставляет желать лучшего. Это привело как представителей науки административного права, так и политических деятелей к пониманию необходимости оценки эффективности реализации административно-правовых средств противодействия коррупции. Более того, на международно-правовом уровне даже существует обязательство по проведению периодической оценки правовых документов и с целью определения их эффективности в борьбе с коррупцией (ч. 3 ст. 5 Конвенции ООН против коррупции).

В целом эффективность проводимой антикоррупционной политики оценивается по следующим критериям: количество принятых нормативных правовых актов по вопросам противодействия коррупции; количество проведенных проверок деятельности органов и должностных лиц; количество выявленных коррупциогенных факторов; количество проведенных антикоррупционных экспертиз; количество возбужденных дел по фактам коррупционных правонарушений и т.п. [2] Именно с помощью таких критериев становиться возможным оценить состояние и уровень коррупции, а также проверить эффективны ли существующие средства борьбы с ней.

Отдельным критерием эффективности правовой нормы в науке признается общественное мнение. Отмечается, что «...общественное мнение, обладая нормативно-регулирующей функцией, распространенностью, устойчивостью и интенсивностью влияет на эффективность правовой нормы, является четким показателем характера и степени общезначимости правовой нормы, а потому известным индикатором социальной полезности цели нормы. Изучение общественного мнения - важный компонент конкретно-социологического анализа эффективности действующей правовой нормы» [3].

Различные критерии эффективности проводимой антикоррупционной политики позволяют оценить соответствует ли существующие административно-правовые средства реальным коррупционным угрозам. Более того, они позволяют выявить соответствует ли существующий антикоррупционный инструментарий специфике коррупционных преступлений той или иной сферы государственного управления и возможности заимствования антикоррупционных средств применимых в других сферах государственной службы. В итоге оценка эффективности мер противодействия коррупции позволяет посредством выявления специфики коррупции в социальной сфере сделать вывод об эффективности отдельных общих административно-правовых средств борьбы с коррупцией в данной сфере; о необходимости адаптации отдельных общих средств борьбы с коррупцией; а также о создании специальных административно-правовых средств противодействия коррупции, применимых только для указанных сфер.

Оценка существующих общих механизмов противодействия коррупции, применяемых в социальной сфере позволяет выявить их неадекватность и изложить отдельные пути их совершенствования. Рассмотрим отдельные примеры таких административно-правовых механизмов.

Одним из таких механизмов является контроль за имущественным состоянием работников социальной сферы. Действительно, данное средство уже апробировано в целом ряде секторов государственной и муниципальной службы, и частично применяется в социальной сфере. Напомним, что необходимость представления сведений о доходах, об имуществе и обязательствах имущественного характера была создана в российском правопорядке именно как одно из средств борьбы с коррупцией. Тем не менее, в соответствии с рядом перечней должностей при назначении на которые и при замещении которых граждане обязаны представлять сведения о своих доходах, расходах, об имуществе и обязательствах имущественного характера, а также сведения о доходах, расходах, об имуществе и обязательствах имущественного характера своих супруги (супруга) и несовершеннолетних детей не 
распространяется на большинство работников социальной сферы. Так, например, Приказ Минздрава России от 15 июля 2013 г. № 462 н «0 перечне должностей, замещаемых на основании трудового договора в организациях, созданных для выполнения задач, поставленных перед Министерством здравоохранения Российской Федерации, при назначении на которые и при замещении которых граждане обязаны представлять сведения о своих доходах, расходах, об имуществе и обязательствах имущественного характера, а также сведения о доходах, расходах, об имуществе и обязательствах имущественного характера своих супруги (супруга) и несовершеннолетних детей» распространяет обязанность предоставлять сведения о доходах лишь на отдельных лиц (чаще всего на руководителя, заместителя руководителя и главного бухгалтера медицинского учреждения).

Аналогичен и подход к данному вопросу и в других секторах социальной сферы. Так, например, в соответствии с Приказом Министерства культуры Российской Федерации от 8 мая 2014 г. № 799 «Об утверждении перечня отдельных должностей в организациях, создаваемых для выполнения задач, поставленных перед Министерством культуры Российской Федерации, при назначении на которые граждане и при замещении которых работники обязаны представлять сведения о своих доходах, об имуществе и обязательствах имущественного характера, а также сведения о доходах, об имуществе и обязательствах имущественного характера своих супруги (супруга) и несовершеннолетних детей» список таких лиц идентичен.

Несовершенство такой системы контроля за имущественным состоянием работников социальной сферы стало очевидным при анализе статистических данных и социальных опросов о коррупции в социальной сфере [4], который показал, что основная масса коррупционных правонарушений совершается на уровне базовых работников социальной сферы. Очевидно, что при таком раскладе данная обязанность не распространяется на большую часть работников сферы здравоохранения, образования и культуры, тогда как основная масса базовых коррупционных правонарушений совершается именно на уровне рядовых сотрудников учреждений социальной сферы, а не руководства учреждений здравоохранения, образования и культуры. Как следствие - и мы не можем не согласиться в этом с отдельными авторами [5] - необходимо расширить ее применение в социальной сфере.

Более того, основная проблема неэффективности института декларирования имущества государственными гражданскими служащими сконцентрирована на региональном и муниципальном уровне, т.е. там где сосредоточена основная масса гражданских служащих социальной сферы. Действительно, по меткому замечанию Т.Я. Хабриевой «больше всего проблем возникает в сфере декларирования государственными служащими субъектов РФ и муниципальными служащими доходов, имущества и обязательств имущественного характера» [6].

Как следствие, специфика коррупции в социальной сфере свидетельствует о неадекватности применения такой общеправовой антикоррупционной меры как имущественный контроль в той форме в которой она применяется к гражданским служащим других сфер государственной и муниципальной службы. Это диктует необходимость адаптации данного административно-правового института посредством расширения его применения в первую очередь на региональном уровне, а также распространение данного обязательства на всех работников социальной сферы. Основными критериями эффективности мер противодействия коррупции, продемонстрировавшим несовершенство действующих инструментов имущественного контроля стали статистические данные, демонстрирующие высокие показатели коррупции на уровне базовых работников социальной сферы, а также общественное мнение свидетельствующее о высоком уровне такой, бытовой коррупции.

Статистический анализ коррупционной активности в социальной сфере, свидетельствующий о том, что основная масса коррупционных преступлений совершается на базовом (бытовом) уровне, а также специализация статуса работников социальной сферы позволяет предложить в качестве основного направления совершенствования эффективности средств борьбы с коррупцией скорректировать отдельные элементы их правового статуса. Речь в частности идет о совершенствовании норм деловой и профессиональной этики работника социальной сферы.

Несмотря на меньшую - в сравнении с антикоррупционным просвещением [7] - эффективность действия норм деловой и профессиональной этики, стоит упомянуть об их значении для совершенствования административно-правовых средств противодействия коррупции в социальной сфере. Принимая во внимание размывание этических принципов в отношениях пациента с врачом, а также преподавателя с обучающимся - которое мы можем наблюдать в процессе «банализации» мелкой (бытовой) коррупции в социальной сфере - значение фиксированных этических принципов поведения в рамках профессиональной деятельности врача и педагога все же не стоит недооценивать. Иначе говоря, специфика мелкой коррупции в социальной сфере, не характеризующаяся в моральных представлениях субъектов как правона- 


\section{Административное и муниципальное право 9 (105) 2016}

рушение, а также повышенная латентность коррупции в социальной сфере, нехарактерные для других сфер государственной и муниципальной службы требуют особого подхода к повышению эффективности реализации административноправовых средств противодействия коррупции. «Представляется целесообразным принятие в России Кодекса корпоративного управления для медицинских работников (а также работников социальной сферы), аналогичного существующим во многих странах мира» [8].

В сфере здравоохранения уже был зафиксирован ряд этических принципов поведения работников данной сферы. Так, Ассоциацией медицинских сестер России был создан «Этический кодекс медицинской сестры», тогда как этические принципы профессиональной деятельности работников сферы здравоохранения в целом были установлены Всероссийским Пироговским съездом врачей в «Кодексе врачебной этики Российской Федерации». Несмотря на неофициальный характер данных текстов, оба содержат ряд положений касающихся борьбы с коррупционными проявлениями в деятельности медицинского персонала. Так, обновленная редакция Этического кодекса медицинской сестры (2010 г.) гласит «Медицинская сестра должна отказываться от подарков и лестных предложений со стороны пациента, если в основе лежит его желание добиться привилегированного положения. Медицинская сестра вправе принять благодарность от пациента, если она выражается в форме, которая не противоречит справедливости и порядочности и не нарушает правовых норм» (ст. 14). В свою очередь, в Кодексе врачебной этики Российской Федерации (п. 4) указано: «Мотивы материальной, личной выгоды не должны оказывать влияния на принятие врачом профессионального решения».

Если антикоррупционные этические принципы в сфере здравоохранения существуют, то дело обстоит иным образом в сфере образования и культуры. Действительно, несмотря на существование кодексов профессиональной этики педагогических работников отдельных учебных заведений, общероссийского Кодекса профессиональной этики учителя не существует, что, на наш взгляд, является довольно критичным, если принять во внимание уровень коррупции в российской системе образования. В тоже время стоит отметить, что Министерством образования и науки Российской Федерации был разработан Модельный кодекс профессиональной этики педагогических работников организаций, осуществляющих образовательную деятельность, который гласит: «...исключать действия, связанные с влиянием каких-либо личных, имущественных (финансовых) и иных интересов, препятствующих добросовестному исполнению трудовых обязанностей (п. 8, ж))». Все же стоит отметить, что помимо того, что данный кодекс был принят лишь совсем недавно (2014 г.), он является модельным и не носит юридической силы, а предполагает необходимость принятия отдельного кодекса на уровне каждого образовательного учреждения, что, конечно же, не способствует единообразному пониманию этических принципов педагогических работников. Было бы намного более эффективно предложить разработать данный документ - наподобие ассоциации медицинских сестер - профсоюзу педагогических работников или ассоциации последних.

Стоит отметить, что ознакомление работников социальной сферы с положениями соответствующих кодексов этики должно происходить еще на стадии профессионального обучения врачей и педагогов. Возможно, стоит объединить процедуру дачи клятвы Гиппократа с клятвой соблюдения этических принципов Кодексов профессиональной этики на стадии обучения и осуществлять данную процедуру в торжественной форме наподобие принесения присяги в милитаризированной сфере государственного управления. Также стоит размещать данные Кодексы в самих учреждениях социальной сферы наподобие книг об отзывах и предложений. Такие предложения возвращают нас к идее необходимости совершенствования антикоррупционного профессионального образования педагогов и врачей, что довольно просто реализовать в связи с необходимостью обязательного прохождения профессиональной подготовки работников данных секторов социальной сферы в рамках учреждений высшего образования.

Таким образом, специфика социальной сферы требует специализированных средств повышения эффективности мер противодействия коррупции, одной их которых является повышение роли принципов морально-этического поведения работников социальной сферы.

Анализ сферы оказания услуг в социальной сфере позволил обратить внимание и на особую роль отдельных общих унифицированных механизмов противодействия коррупции. Так, например, такая особенность предоставления услуг в социальной сфере, как наличие частных хозяйствующих субъектов, предоставляющих медицинские и образовательные услуги, свидетельствует о первостепенной важности административно-правового регулирования конфликта интересов.

Формирование и развитие норм административного права регулирующих разрешение конфликта интересов в системе публичной службы является одним из основных направлений в деле совершенствования противодействия коррупции 
в социальной сфере. Обусловлено это тем, что в данной сфере государственного управления исполнение некоторых публичных функций предоставляется негосударственным хозяйствующим субъектам. Как следствие, осуществление таких практик как развитие собственного бизнеса за счет, государственных (муниципальных) медицинских и образовательных учреждений или организаций является здесь дольно распространенной коррупционной практикой.

Напомним, что понятие конфликта интересов появилось в российском законодательстве сравнительно недавно и связано с принятием Федерального закона от 27 июля 2004 г. «О государственной гражданской службе Российской Федерации», а также с имплементацией в российский правопорядок Конвенции ООН против коррупции. Именно обозначенная конвенция определила понятие конфликта интересов, как ситуацию, при которой возникает воздействие на непредвзятое и объективное исполнение служащим своих должностных обязанностей. Стоит отметить, что в соответствии с данным понятием конфликта интересов - т.е. как ситуации, при которой государственный (муниципальный) служащий, располагая личной заинтересованностью, подвергается отрицательному влиянию на объективность и беспристрастность при выполнении им своих должностных обязанностей социальная сфера является наиболее подверженной данному феномену. Действительно, анализ сравнительной практики применения данного понятия в сфере публичного управления позволяет отметить, что ситуаций, при которых возникает конфликт интересов именно в социальной сфере, больше чем где бы то ни было в сфере публичного управления.

Если в различных сферах государственного управления конфликт интересов возникает в связи с корпоративными интересами, то в социальной сфере, где существует возможность возникновения конфликта интересов, он возникает вследствие такой личной заинтересованности, когда работник социальной сферы может оказывать соответствующие услуги и как служащий публичной службы и как работник негосударственной структуры оказывающей социальные услуги, конкурирующей с государственными или муниципальными социально-культурными учреждениями и организациями.

Определенное несовершенство действующего законодательства регламентирующего отношения в социальной сфере в части разрешения конфликта интересов вполне очевидно. Так, ограничения установлены в отношении служащих государственной и муниципальной службы в части занятия предпринимательской деятельностью лично или через доверенных лиц, а также участия в управле- нии хозяйствующим субъектом и получении в связи с исполнением должностных обязанностей вознаграждения от физических и юридических лиц. В тоже время, как в части предоставления платных услуг в рамках государственных и муниципальных образований, так и предоставления аналогичных услуг в рамках частных хозяйствующих субъектов вопрос конфликта интересов не урегулирован. Как следствие, вопросы конфликта интересов в социальной сфере требуют дальнейшей детализации, а его конкретная реализация возможна, например, посредством установления обязанностей работников социальной сферы по уведомлению своего руководства о возникшем конфликте интересов или о возможности его возникновения и т.п.

Стоит обратить внимание на наиболее широкое применение помимо уголовной, административной ответственности за коррупционные правонарушения, также и дисциплинарной ответственности за них. Данный вопрос уже обсуждался в науке административного права без привязки к коррупционным правонарушениям, совершаемым в социальной сфере. Антикоррупционный потенциал дисциплинарной ответственности в науке объясняется ее субсидиарным - по отношению к уголовной и административной ответственности характером. Иначе говоря, если уже использующиеся виды ответственности за коррупционные правонарушения в социальной сфере сегодня не рассматриваются как эффективные, то потенциал дисциплинарной ответственности как дополнительного наказания за коррупционные правонарушения на сегодняшний день и вовсе не раскрыт, хотя и может быть использован в качестве дополнительного антикоррупционного средства реализуемого в социальной сфере.

Конечно же, основанием дисциплинарной ответственности работника - в том числе и социальной сферы - является нарушение правил дисциплины и других обязанностей, возложенных на него в связи с его работой, учебой и иной трудовой (служебной) деятельностью, т.е. трудового права, а не административного или уголовного законодательства [9]. Как следствие, данный вид ответственности, на первый взгляд, не приспособлен для антикоррупционных целей. В тоже время, не существует нормативного материала прямо запрещающего устанавливать в качестве одной из обязанностей трудового договора запрет на совершение коррупционных действий и предусматривающего в качестве наказания за их несоблюдение одно из дисциплинарных взысканий предусмотренных Трудовым кодексом (ст. 192). Как следствие, на наш взгляд, министерствам здравоохранения, культуры и образования (федеральным и субъектов федерации) стоит задуматься о создании типовых 


\section{Административное и муниципальное право 9 (105) • 2016}

(модельных) трудовых договоров заключаемых с работниками социальной сферы, в которых обязанность работника не совершать коррупционные правонарушения была бы одним из обязательных условий таких договоров, а за ее нарушение была бы предусмотрена дисциплинарная ответственность работника.

Пути повышения эффективности реализации административно-правовых средств противодействия коррупции в социальной сфере могут осуществляется не только посредством специализированно адаптированных для данной сферы средств (таких например как установление норм деловой этики), но и общих мер (таких например как имущественный контроль). К последним стоит отнести и совершенствование координации действий правоохранительных органов в борьбе с коррупцией.

Совершенствование координации действий правоохранительных органов в борьбе с коррупцией является одним из направлений совершенствования противодействия коррупции. Данный вопрос наиболее явным образом встал на повестке дня в связи с введением контроля за имущественным положением государственных и муниципальных служащих. Действительно, если основным субъектом, на плечи которого была возложена данная функция стала Прокуратура РФ [10], то на практике выполнение данной функции требует непосредственного взаимодействия органов прокуратуры с различными органами финансового, бюджетного и иного контроля, в частности следственных органов, Счетной палаты, финансового мониторинга и др. Если такая координационная функция уже возложена на прокуратуру в рамках действующего законодательства, то ее практическая реализация далека от идеала. Отдельные авторы даже высказывают по данному поводу мнение, что на сегодняшний день отсутствует четкая и стройная организационно-структурная система осуществления координационной деятельности прокуратуры по борьбе с коррупцией [11].

Так, например, одним из недостатков существующей системы выявления и раскрытия наиболее распространённых преступлений в сфере ЖКХ является несогласованность действий контрольно-надзорных органов. Действительно, отмечается, что для эффективной борьбы с коррупцией в данном секторе социальной сферы необходимо «организовывать внешнее взаимодействие и привлечь к проверке сотрудников Межрегионального территориального управления службы Финансово-бюджетного надзора, департаментов финансово-бюджетного надзора территориального и регионального уровней, сотрудников Счетной палаты регионального и территориального уровней для проведения расширенных проверочных мероприятий» [12].

В сфере образования и здравоохранения существующие институциональные основы контроля и надзора могут стать ключевым элементом в системе взаимодействия органов государственной власти в борьбе с коррупцией в данной сфере. В тоже время, если в сфере здравоохранения Федеральная служба по надзору в сфере здравоохранения обладает территориальными подразделениями которые частично выполняют работу по взаимодействию с правоохранительными органами в борьбе с коррупцией, то Федеральная служба по надзору в сфере образования и науки не обладает такими территориальными подразделениями. В науке административного права отмечается по данному поводу, что «...действующий порядок разграничения полномочий в образовательной политике при учете имеющейся структуры федерального надзорного органа в сфере образования не в состоянии обеспечить должный надзор за деятельностью высших учебных заведений, а соответственно - противостоять распространению коррупции» [13].

Очевидно, что в свете распространения имущественного контроля государственных и муниципальных служащих на работников социальной сферы стоит задуматься и о создании постоянно действующих координационных структур в рамках органов прокуратуры и с участием соответствующих профильных надзорных органов социальной сферы. Это связано с тем, что отдельные органы государственной власти, не входящие в структуру органов прокуратуры (финансового мониторинга, налогового контроля и т.п.) располагают наиболее адекватным для проведения контрольных действий в отношении имущественного состояния служащих набором специализированных функций и средств, необходимых для выявления, пресечения, раскрытия и расследования преступлений коррупционной направленности. В случае введения имущественного контроля в отношении работников социальной сферы, координация деятельности по борьбе с коррупцией в них должна будет также осуществляться и с органами (как федеральными, так и субъектов федерации) здравоохранения, образования и культуры. Как следствие, их систематическое привлечение в рамках следственных действий позволит более эффективно выявлять коррупционные действия государственных и муниципальных служащих.

Таким образом, пути повышения эффективности реализации административно-правовых средств противодействия коррупции в социальной сфере осуществляются посредством оценки эффективности применяемых антикоррупционных средств; оценке адекватности применения общих 
унифицированных средств в социальной сфере; адаптации общих антикоррупционных средств к специфике социальной сферы; наконец, посредством разработки специальных антикоррупционных средств наиболее адаптированных к борьбе с коррупцией в социальной сфере. Разработка таких механизмов осуществляется на основе анализа ста- тистических данных, социологических опросов, а, шире, на основе конкретных недостатков выявленных в процессе применения антикоррупционных механизмов. Именно анализ последних позволяет сформулировать пути повышения эффективности реализации административно-правовых средств противодействия коррупции в социальной сфере.

\section{Библиография:}

1. Пашков А.С., Явич Л.С. Эффективность действия правовой нормы // Советское государство и право. 1970. № 3. C. 42.

2. Хазанов С.Д. К вопросу формирования механизмов оценки эффективности мер противодействия коррупции в Российской Федерации // Следователь. 2013. № 1. С. 59.

3. Бонк Е.Л. Общественное мнение и эффективность юридической нормы // Правоведение. 1979. № 5. С. 44.

4. Чеснокова М.Д. Правовой мониторинг в социальной сфере // Журнал российского права. 2009. № 4. С. 21.

5. Годованный А.В. Противодействие коррупции в системе образования России: правовой аспект // Борьба с коррупцией в системе государственного и муниципального управления. Новосибирск, 2011. С. 236.

6. Хабриева Т.Я., Андриченко Л.В., Цирин А.М. О результатах анализа практики реализации программ противодействия коррупции в субъектах РФ и предложениях по повышению эффективности // Журнал Российского права. 2012. № 11. С. 64.

7. Ельцова Е.М. Коррупция в сфере образования // Государство и право: история и современность. Пермь, 2013. C. 17.

8. Хасанов Ф.З. Общая характеристика коррупции в сфере здравоохранения // Законодательство. 2015. № 5. С. 64.

9. Вифлеемский А.Б. Специфические основания привлечения к дисциплинарной ответственности педагогических работников // Отдел кадров бюджетного учреждения. 2009. № 6. С. 45.

10. Винокуров А.Ю. Контроль за соответствием расходов лиц, замещающих государственные должности, и иных лиц их доходам как самостоятельная функция прокуратуры // Административное и муниципальное право. 2013. № 2. С. 108.

11. Кобзарев Ф.М. Об особенностях и проблемах организации координационной деятельности прокуратуры по борьбе с коррупцией // Вестник Академии Генеральной прокуратуры Российской Федерации. 2010. № 3. С. 21.

12. Спиридонов С.А. Выявление и раскрытие преступлений коррупционной направленности в сфере жилищно-коммунального хозяйства оперативными подразделениями органов внутренних дел. Домодедово, 2015. С. 38.

13. Богданов А.В. Правовые механизмы противодействия коррупции в сфере образования // Вестник Тюменского государственного университета. 2010. № 2. С. 50.

14. Костенников М.В., Куракин А.В. К вопросу об основании административной ответственности в российском праве // NB: Административное право и практика администрирования. 2013. № 10. C. 75 - 88. DOI: 10.7256/23069945.2013.10.10153. URL: http://www.e-notabene.ru/al/article_10153.html

15. Костенников М.В., Куракин А.В. Административно-правовое противодействие коррупции в системе государственной службы и в деятельности сотрудников полиции Российской Федерации и зарубежных государств // Полицейская деятельность. 2011. - 1. С. 10 - 16.

16. Костенников М.В., Куракин А.В., Ватель А.Ю. Антикоррупционные и этические стандарты служебного поведения государственных гражданских служащих // Полицейская и следственная деятельность. 2014. - 2. C. 52 - 76. DOI: 10.7256/2409-7810.2014.2.13873. URL: http://www.e-notabene.ru/pm/article_13873.html

17. Саидов 3.А., Куракин А.В. Актуальные проблемы противодействия полиции административным правонарушениям в сфере предпринимательства // Полицейская деятельность. 2015. - 5. С. 257 - 275. DOI: 10.7256/22221964.2015.5.16481.

18. Костенников М.В., Куракин А.В., Ватель А.Ю. Антикоррупционные и этические стандарты служебного поведения государственных гражданских служащих // NB: Административное право и практика администрирования. 2014. - 4. C. 15 - 39. DOI: 10.7256/2306-9945.2014.4.12248. URL: http://www.e-notabene.ru/al/article_12248.html

\section{References (transliterated):}

1. Pashkov A.S., Yavich L.S. Effektivnost' deistviya pravovoi normy // Sovetskoe gosudarstvo i pravo. 1970. № 3. S. 42.

2. Khazanov S.D. K voprosu formirovaniya mekhanizmov otsenki effektivnosti mer protivodeistviya korruptsii v Rossiiskoi Federatsii // Sledovatel'. 2013. № 1. S. 59.

3. Bonk E.L. Obshchestvennoe mnenie i effektivnost' yuridicheskoi normy // Pravovedenie. 1979. № 5. S. 44.

4. Chesnokova M.D. Pravovoi monitoring v sotsial'noi sfere // Zhurnal rossiiskogo prava. 2009. № 4. S. 21.

5. Godovannyi A.V. Protivodeistvie korruptsii v sisteme obrazovaniya Rossii: pravovoi aspekt // Bor'ba s korruptsiei v sisteme gosudarstvennogo i munitsipal'nogo upravleniya. Novosibirsk, 2011. S. 236.

6. Khabrieva T.Ya., Andrichenko L.V., Tsirin A.M. O rezul'tatakh analiza praktiki realizatsii programm protivodeistviya korruptsii v sub"ektakh RF i predlozheniyakh po povysheniyu effektivnosti // Zhurnal Rossiiskogo prava. 2012 . № 11. S. 64 . 


\section{Административное и муниципальное право 9 (105) • 2016}

7. El'tsova E.M. Korruptsiya v sfere obrazovaniya // Gosudarstvo i pravo: istoriya i sovremennost'. Perm', 2013. S. 17.

8. Khasanov F.Z. Obshchaya kharakteristika korruptsii v sfere zdravookhraneniya // Zakonodatel'stvo. 2015 . № 5. S. 64.

9. Vifleemskii A.B. Spetsificheskie osnovaniya privlecheniya k distsiplinarnoi otvetstvennosti pedagogicheskikh rabotnikov // Otdel kadrov byudzhetnogo uchrezhdeniya. 2009. № 6. S. 45.

10. Vinokurov A.Yu. Kontrol' za sootvetstviem raskhodov lits, zameshchayushchikh gosudarstvennye dolzhnosti, i inykh lits ikh dokhodam kak samostoyatel'naya funktsiya prokuratury // Administrativnoe i munitsipal'noe pravo. 2013. № 2. S. 108.

11. Kobzarev F.M. Ob osobennostyakh i problemakh organizatsii koordinatsionnoi deyatel'nosti prokuratury po bor'be s korruptsiei // Vestnik Akademii General'noi prokuratury Rossiiskoi Federatsii. 2010. № 3. S. 21.

12. Spiridonov S.A. Vyyavlenie i raskrytie prestuplenii korruptsionnoi napravlennosti v sfere zhilishchno-kommunal'nogo khozyaistva operativnymi podrazdeleniyami organov vnutrennikh del. Domodedovo, 2015. S. 38.

13. Bogdanov A.V. Pravovye mekhanizmy protivodeistviya korruptsii v sfere obrazovaniya // Vestnik Tyumenskogo gosudarstvennogo universiteta. 2010. № 2. S. 50.

14. Kostennikov M.V., Kurakin A.V. K voprosu ob osnovanii administrativnoi otvetstvennosti v rossiiskom prave // NB: Administrativnoe pravo i praktika administrirovaniya. 2013. № 10. C. 75 - 88. DOI: 10.7256/2306-9945.2013.10.10153. URL: http://www.e-notabene.ru/al/article_10153.html

15. Kostennikov M.V., Kurakin A.V. Administrativno-pravovoe protivodeistvie korruptsii v sisteme gosudarstvennoi sluzhby i v deyatel'nosti sotrudnikov politsii Rossiiskoi Federatsii i zarubezhnykh gosudarstv // Politseiskaya deyatel'nost'. 2011. - 1. C. $10-16$.

16. Kostennikov M.V., Kurakin A.V., Vatel' A.Yu. Antikorruptsionnye i eticheskie standarty sluzhebnogo povedeniya gosudarstvennykh grazhdanskikh sluzhashchikh // Politseiskaya i sledstvennaya deyatel'nost'. 2014. - 2. C. 52 - 76. DOI: 10.7256/2409-7810.2014.2.13873. URL: http://www.e-notabene.ru/pm/article_13873.html

17. Saidov Z.A., Kurakin A.V. Aktual'nye problemy protivodeistviya politsii administrativnym pravonarusheniyam v sfere predprinimatel'stva // Politseiskaya deyatel'nost'. 2015. - 5. C. 257 - 275. DOI: 10.7256/2222-1964.2015.5.16481.

18. Kostennikov M.V., Kurakin A.V., Vatel' A.Yu. Antikorruptsionnye i eticheskie standarty sluzhebnogo povedeniya gosudarstvennykh grazhdanskikh sluzhashchikh // NB: Administrativnoe pravo i praktika administrirovaniya. 2014 . - 4. C. 15 - 39. DOI: 10.7256/2306-9945.2014.4.12248. URL: http://www.e-notabene.ru/al/article_12248.html 